Letrônica, Porto Alegre, v. 7, n. 1, p. 4-25, jan./jun., 2014

\title{
A SENSIBILIDADE DE BEBÊS BRASILEIROS A PISTAS PROSÓDICAS DE FRONTEIRAS DE SINTAGMA ENTOACIONAL NA FALA DIRIGIDA À CRIANÇA ${ }^{1}$
}

\section{BRAZILIAN INFANTS' SENSITIVITY TO PROSODIC CUES OF INTONATIONAL PHRASE BOUNDARIES ON INFANT DIRECTED SPEECH}

\author{
Ícaro Oliveira Silva* \\ Cristina Name**
}

\begin{abstract}
Resumo: 0 presente trabalho investiga se bebês brasileiros são capazes de analisar acusticamente o sinal linguístico, de modo a identificar os limites de palavras e sentenças de sua língua (cf. os constituintes prosódicos em NESPOR e VOGEL, 1986; PIERREHUMBERT, 1980; LADD, 2008). Focalizamos a sensibilidade a propriedades prosódicas de fronteiras de Sintagma Entoacional (I) em enunciados de Fala Dirigida à Criança (FDC) e seu uso na segmentação e reconhecimento lexical pelo bebê. Duas atividades foram desenvolvidas: a primeira analisa enunciados de FDC coletados em situações de interação entre mãe e bebês brasileiros, de modo a identificar as propriedades prosódicas que delimitam as fronteiras de I; a segunda, experimental, verifica se bebês brasileiros, com média de 13 meses de idade, são sensíveis a essas propriedades e se as utilizam para identificar uma palavra previamente familiarizada. Os resultados sugerem que tais propriedades são percebidas pelos bebês, que fazem uso delas como pistas para segmentar o continuum sonoro em unidades gramaticalmente significativas. Defendemos que as informações acústicas disponíveis nas fronteiras de constituintes prosódicos são ampliadas na FDC (SEIDL; CRISTIÀ, 2008) e podem facilitar o desencadeamento do processo de aquisição da linguagem (cf. Hipótese do Bootstrapping Prosódico: MORGAN; DEMUTH, 1996; CHRISTOPHE et al., 1997).
\end{abstract}

Palavras-chave: Aquisição da Linguagem; Fonologia; Prosódia; Sintagma Entoacional; Português Brasileiro.

\begin{abstract}
This study investigates whether Brazilian infants are able to analyze acoustic properties of linguistic input in order to perceive word and sentence boundaries (cf. NESPOR; VOGEL, 1986; PIERREHUMBERT, 1980; LADD, 2008). The focus of the study is on infant sensitivity to prosodic cues of Intonational Phrase (I) boundaries on Infant Directed Speech (IDS) stimuli; and on their ability to use cues in word discrimination tasks. Two activities were carried out: the first activity analyzed IDS utterances extracted from Brazilian mother-baby social interaction in order to identify prosodic properties of I-boundaries; the.
\end{abstract}

${ }^{1}$ Trabalho desenvolvido no âmbito de projetos de pesquisa apoiados pelo CNPq (Processos de números. 485171/2012-0 e 401510/2010-7), aprovados pelo Comitê de Ética em Pesquisa/UFJF (Pareceres números. 254.263/2013 e 100/2011, respectivamente).

* Doutorando em Linguística pelo Programa de Pós-Graduação em Linguística da Universidade Federal de Juiz de Fora. Mestre em Linguística pela mesma instituição, tendo sido bolsista CAPES. Este artigo é fruto da dissertação de mestrado, intitulada A sensibilidade de bebês brasileiros a fronteiras de sintagma entoacional: a prosódia nas fases iniciais da aquisição da linguagem, defendida em março de 2014.

${ }^{* *}$ Professora Associada da Universidade Federal de Juiz de Fora; Coordenadora do NEALP/UFJF (Núcleo de Estudos em Aquisição da Linguagem e Psicolinguística); Bolsista de Produtividade em Pesquisa CNPq. 
Second activity, an experimental one, tested whether 13-month Brazilian infants are sensitive to these properties and use them to discriminate a word with which they were familiar. The results suggest that prosodic I-boundary cues were perceived by babies and facilitated word segmentation. We argue that acoustic information presented in prosodic constituents boundaries are amplified on IDS stimuli and may facilitate language acquisition bootstrapping (cf. Prosodic Bootstrapping Hypothesis: MORGAN; DEMUTH, 1996; CHRISTOPHE et al., 1997).

Keywords: Language Acquisition; Phonology; Prosody; Intonational Phrase; Brazilian Portuguese.

\section{Introdução}

Durante o processo de aquisição da linguagem, os bebês passam por diversas etapas de desenvolvimento linguístico, as quais requerem diferentes habilidades cognitivas. No que se refere à identificação do vocabulário, o bebê tem de ser capaz de segmentar o fluxo de fala em unidades menores - no entanto, as relações que se estabelecem entre o som e o significado são bastante arbitrárias. Assim, relacionar a informação acústica disponível nos enunciados linguísticos a palavras parece ser uma tarefa complicada, uma vez que não há, na fala fluente, marcadores explícitos que delimitem o início e o fim dos vocábulos (MEHLER; CHRISTOPHE, 1994).

Modelos de processamento do sinal acústico da fala por adultos (MCCLELLAND; ELMAN, 1986; NORRIS, 1994, por exemplo) assumem que os falantes/ouvintes tomam como base o léxico, isto é, ativam os itens lexicais compatíveis com as informações fonéticas que recebem enquanto processam os estímulos linguísticos. Quando um determinado fonema ou sílaba é compatível com mais de uma palavra, instaura-se um processo de competição entre essas palavras, que só se estabiliza quando a informação fonética é suficiente para restringir o acesso ao item desejado. Tal estratégia, no entanto, não se aplica aos bebês, uma vez que eles ainda não possuem vocabulário. Assim, outros recursos são necessários para que os infantes possam segmentar a cadeia da fala e dela extrair unidades lexicais.

Neste artigo, investigamos a habilidade de bebês brasileiros com média de idade de treze meses em segmentar os enunciados linguísticos a partir de pistas de fronteira de sintagma entoacional. Assumimos, a partir da hipótese do Bootstrapping Prosódico (MORGAN; DEMUTH, 1996; CHRISTOPHE et al., 1997), que bebês são capazes de analisar acusticamente o sinal linguístico, o que lhes permite descobrir os limites de palavras e sentenças de sua língua. 
Defendemos, ainda, que a Fala Dirigida à Criança (doravante, FDC) tem um papel facilitador e desencadeador desse processo (SEIDL; CRISTIÀ, 2008), ao ampliar propriedades acústicas delimitadoras de constituintes prosódicos e, consequentemente, favorecer a percepção, pelo bebê, de níveis prosódicos hierarquicamente dispostos (cf. NESPOR; VOGEL, 1986). Interessa-nos, particularmente, o sintagma entoacional (I), elemento da hierarquia prosódica muito recorrente na FDC e responsável por definir o contorno entoacional de um enunciado linguístico.

Para isso, desenvolvemos duas atividades: a primeira analisa enunciados de FDC coletados em situações de interação mãe/bebê brasileiros, de modo a identificar as propriedades prosódicas que delimitam as fronteiras de I; a segunda, experimental, investiga a sensibilidade de bebês brasileiros com média de idade de treze meses a essas fronteiras.

Na próxima seção, discorreremos brevemente sobre organização prosódica da fala e da FDC. Focalizaremos o sintagma entoacional, com base nas propostas da Fonologia Prosódica (NESPOR; VOGEL, 1986) e da Fonologia Entoacional (PIERREHUMBERT, 1980; LADD, 2008). A seção 2 apresenta as atividades desenvolvidas no âmbito deste trabalho: a coleta e análise de dados de FDC e o experimento com os bebês. Por fim, na conclusão, retomamos nossos resultados considerando o papel do sintagma entoacional no processo de aquisição de uma língua pelo bebê.

\section{A estrutura suprassegmental da Fala Dirigida à Criança}

\subsection{A Organização Prosódica da Fala}

De acordo com a Fonologia Prosódica (NESPOR; VOGEL, 1986), os enunciados linguísticos podem ser organizados em constituintes fonológicos dispostos hierarquicamente. Tais constituintes são definidos com base em regras de mapeamento, que consideram informações relativas à morfologia e à sintaxe, e em regras fonológicas, cuja aplicação/restrição no interior ou na fronteira de constituintes oferece evidências para a postulação dos domínios prosódicos. Ainda que os princípios que governam esses domínios considerem informações de níveis não fonológicos, não há, obrigatoriamente, 
uma relação isomórfica com os constituintes morfológicos e/ou sintáticos. Os níveis mínimo e máximo dessa hierarquia são, respectivamente, a sílaba e o enunciado fonológico. Abaixo deste, encontram-se o sintagma entoacional e o sintagma fonológico, níveis em que se estabelece a interface entre prosódia e sintaxe.

O sintagma entoacional (I), focalizado neste trabalho, pode ser constituído por um conjunto de sintagmas fonológicos ou por apenas um sintagma fonológico, desde que seja portador de uma linha entoacional. A regra básica de formação de um I está baseada na noção de que esse constituinte é o domínio do contorno entoacional e que o fim deste coincide com posições nas quais pausas podem ser introduzidas nas sentenças (NESPOR; VOGEL, 1986). No domínio de um I, informações fonológicas interagem, principalmente, com informações provenientes do nível sintático e semântico da língua. Ainda de acordo com essas autoras, esse constituinte prosódico pode sofrer processos de reestruturação, que são determinados por quatro fatores principais: o tamanho da frase, a velocidade da fala, o estilo e a proeminência relativa.

Como o I está intimamente relacionado ao padrão entoacional dos enunciados linguísticos, faz-se necessário considerar, em sua caracterização, os pressupostos teóricos da Fonologia Entoacional (PIERREHUMBERT, 1980; LADD, 2008). A Fonologia Entoacional configura-se como uma abordagem da estrutura entoacional que considera que a entoação tem uma organização fonológica própria, isto é, a melodia dos enunciados linguísticos constitui um nível independente de outros aspectos fonológicos. Assim, conforme defende Frota (2000), as propriedades entoacionais são consideradas como uma entre outras pistas para a estrutura prosódica.

Os elementos básicos que constituem o sistema entoacional são os tons, compreendidos como unidades contrastivas que estabelecem os contornos melódicos da fala. De acordo com os princípios dessa teoria, a frequência fundamental (F0) pode ser tomada como uma sequência de elementos fonológicos discretos: os eventos tonais. Gussenhoven (2004) argumenta que a F0 é o traço mais significativo na determinação do padrão entoacional de um enunciado. As modulações de F0 são percebidas pelos ouvintes como variações de altura melódica, isto é, como variações entre sons mais graves ou mais agudos. Esse correlato perceptual da F0 recebe o nome de pitch. Quanto maior o valor da F0, mais alto é o valor do pitch; temos, então, a percepção de um som mais agudo. Quanto menor o valor da F0, mais baixo é o pitch, e o som será percebido 
como mais grave. Assim, conforme Ladefoged (2001), o pitch é a propriedade auditiva que permite ao ouvinte dispor, em uma escala de grave a agudo, as variações de F0 de um som por ele percebidas.

Pierrehumbert (1980) defende que os dois tipos de eventos tonais suficientes para descrever as variações de F0 são os acentos tonais (pitch accents) e os tons de fronteira (boundary tones). Os acentos tonais estão relacionados a fronteiras de constituintes mais baixos na hierarquia prosódica, como a palavra prosódica e o sintagma fonológico. Os tons de fronteira, por sua vez, estão associados a fronteiras de constituintes mais altos, como o I e o enunciado fonológico. Ainda de acordo com a autora, os dois níveis de tons primários - que dizem respeito à altura do som - que constituem os acentos tonais e os tons relacionados a fronteiras são os tons altos $(\mathrm{H}$ high tones) e os tons baixos ( $\mathrm{L}$ - low tones). Esses dois tons primários podem dar origem a tons simples ou a tons complexos. Os tons simples são representados por $\mathrm{H}^{*}$ ou $\mathrm{L}^{*}$, nos quais o asterisco sinaliza as sílabas tônicas. Os tons complexos são formados por combinações de tons simples, podendo ser representados por $H^{*}+L, H+L^{*}, L^{*}+H$ ou $\mathrm{L}+\mathrm{H}^{*}$. Os tons de fronteira, por outro lado, são associados aos limites de domínios prosódicos, como o I, sendo representados por $\mathrm{H} \%$ ou L\%. Os acentos frasais, associados a fronteiras intermediárias, são representados por H- ou L-.

Essas propriedades acústicas também são encontradas na FDC - e realçadas -, de modo que podem ser fonte privilegiada de informação para o bebê, como veremos a seguir.

\subsection{A Fala Dirigida à Criança}

Em muitas sociedades humanas, é comum que os adultos, e até mesmo as crianças mais velhas, modifiquem sua fala quando interagem com bebês, utilizando, nesse contexto, a Fala Dirigida à Criança (FDC). Ainda que não possua um caráter universal2 $^{2}$, a FDC é utilizada por homens e mulheres em diferentes comunidades linguísticas (FERNALD et al., 1989; WEPPELMAN et al., 2003; SODERSTROM, 2007; LEE; DAVIS; MACNEILAGE, 2008; MATSUOKA; NAME, 2011; CAVALCANTE; BARROS, 2012).

\footnotetext{
2 Ochs e Schieffelin (1995) apresentam uma série de estudos realizados em comunidades de fala que desconsideram a participação dos bebês nas interações conversacionais.
} 
Uma série de estudos realizados em diversas línguas oferece evidências de que as características prosódicas da FDC são as que mais se destacam quando comparamos esse registro à Fala Dirigida ao Adulto (FDA): contornos de altura bastante exagerados, grande variação na curva de F0, parâmetro prosódico que exibe valores elevados em comparação à FDA, velocidade mais lenta, presença de pausas mais prolongadas e alongamento de vogais e sílabas (MANNEL; FRIEDERICI, 2009; ver CAVALCANTE; BARROS, 2012).

Cavalcante e Barros (2012), analisando dados de interações mãe-bebê brasileiros, observaram mudanças na FDC em função do crescimento do bebê. Inicialmente, a fala materna se desdobra em fala da mãe e fala do bebê, através do falsetto. Conforme o bebê cresce e se torna mais ativo linguisticamente, a fala da mãe vai se tornando prosodicamente mais "natural".

Soderstrom (2007) argumenta que parâmetros prosódicos realçados têm sido apontados como um mecanismo para capturar a atenção do bebê e demonstrar afeto. Esse caráter afetivo e sinalizador da FDC pode ser considerado como facilitador do desenvolvimento da linguagem, uma vez que desperta o interesse do bebê pelo sinal linguístico. Do mesmo modo, as características suprassegmentais da FDC podem oferecer aos bebês informações que facilitam a aquisição da língua materna.

Como é possível observar, as propriedades suprassegmentais da FDC vêm sendo investigadas em diversas línguas. Entretanto, no português brasileiro (PB), ainda não existem estudos que se debruçam sobre as informações acústicas que sinalizam as fronteiras de constituintes prosódicos nesse registro de fala.

Objetivando verificar quais são, na FDC, as informações acústicas que delimitam as fronteiras de I no PB, realizamos gravações acústicas da interação entre mãe e bebê. Em seguida, investigamos, através de uma atividade experimental, se bebês adquirindo o PB como língua materna são capazes de perceber tais propriedades e de que forma utilizam-nas no processamento do sinal acústico da fala. Essas atividades serão descritas na próxima seção. 


\section{As informações prosódicas sinalizadoras de fronteiras de sintagma entoacional (I) na FDC brasileira e sua percepção por bebês em fase inicial da aquisição do PB}

\subsection{Coleta e análise de enunciados de FDC no PB}

Os dados analisados foram coletados em situações de interação entre uma mãe falante nativa do PB e seu bebê, do sexo feminino, com idade de 11 meses, em fase inicial de aquisição da linguagem. Como controle, foram gravados, também, trechos da interação dessa mesma mãe com indivíduos adultos.

As gravações foram realizadas durante visitas semanais à casa da criança, com duração média de 30 minutos, durante dois meses, entre os 11 e os 12 meses de idade do bebê. Essas visitas ocorriam, geralmente, no momento em que a mãe estava dando banho no bebê, quando este era alimentado, ou em situações de brincadeiras, nas quais a criança interagia com a mãe. As interações foram registradas com o auxílio de um gravador de voz digital (SONY PCM-D50). Posteriormente, as dados obtidos foram analisados acusticamente através do software PRAAT (BOERSMA; WEENINK, 2013).

Conforme apresentado anteriormente, nossa análise priorizou os domínios do I na FDC, com o objetivo de descrever quais são, nesse registro, as propriedades acústicas que sinalizam as fronteiras desse constituinte. Para este trabalho, consideramos 30 enunciados produzidos pela mãe, entre sentenças mais longas, formadas por até seis palavras, e construções constituídas de até duas palavras e demarcamos, nesse material, os Is. Foram analisadas 20 ocorrências de I. Os dados selecionados apresentam enunciados menores, muitos destes constituídos de palavras isoladas. Essa configuração vai ao encontro de estudos anteriores realizados no inglês e no português europeu (PE), os quais evidenciam que a FDC exibe enunciados menores e com estrutura sintática mais simples do que aqueles encontrados na FDA (SNOW, 1972; FERNALD; HURTADO, 2006; FROTA; BUTLER; VIGÁRIO, 2013). Esses dados foram comparados com as produções linguísticas da participante em situações de interação com adultos. Essa comparação permitiu-nos concluir que as características acústicas que sinalizam as fronteiras de I nos dois registros de fala (FDC e FDA) são muito semelhantes. No entanto, na FDC, essas propriedades tendem a ser ampliadas, sendo, assim, mais salientes. As análises acústicas revelaram: 
(i) valores de F0 bastante elevados na FDC, atingindo picos de $500 \mathrm{~Hz}$, enquanto na FDA tais valores giram em torno dos $350 \mathrm{~Hz}$;

(ii) grande ocorrência de alongamentos de vogais tônicas das palavras, principalmente quando a mãe tem o objetivo de chamar a atenção do bebê para um elemento ou situação presente na cena da interação, e em posições préfronteira de constituintes prosódicos e sintáticos, com alongamentos maiores no final de sentenças. As medidas de duração obtidas na análise da FDC foram maiores do que aquelas encontradas na FDA, isto é, a FDC apresenta uma cadência mais lenta, com prolongamento de palavras e expressões. Na FDA, a mãe produz os enunciados com uma velocidade maior e, quando há alongamentos, estes são muito menores do que os encontrados na FDC;

(iii) pausas recorrentes e mais prolongadas na FDC do que aquelas observadas na FDA, o que acaba por originar uma fala de velocidade menor;

(iv) Is menores na FDC, muitas vezes formados por uma ou duas palavras;

(v) contorno entoacional fall-rise como demarcador de uma fronteira de I, ou seja, há um declive na curva de F0 no fim de um I, seguido de uma reposição do nível do tom no início do I seguinte; em outros termos, o valor da F0 das sílabas pósfronteira (455 $\mathrm{Hz}$ em média) é maior do que o valor das sílabas pré-fronteira ( $247 \mathrm{~Hz}$ em média), e

(vi) tom de fronteira baixo (L\%) em posição pré-fronteira, seguido de tom com tessitura alta (tom $\mathrm{H}$ ou $\mathrm{H}^{+} \mathrm{L}^{*}$ ) na posição pós-fronteira, o que nos permite concluir que o contorno entoacional típico de I é o ascendente-descendente.

A partir das análises empreendidas nessa atividade, pudemos averiguar quais são, na FDC, as propriedades prosódicas que delimitam as fronteiras de I. Essas propriedades foram encontradas em dados espontâneos, o que nos sugere que elas são, de fato, produzidas na interação com os bebês. De posse desses resultados, buscamos verificar se bebês brasileiros, com média de idade de 13 meses, são capazes de perceber essas informações acústicas e se as utilizam como pistas para a segmentação do fluxo da fala. 


\subsection{A sensibilidade de bebês brasileiros às propriedades acústicas presentes nas fronteiras de sintagma entoacional (I)}

Estudos anteriores, realizados em diferentes línguas, evidenciaram que os bebês, nas fases iniciais do processo de aquisição da linguagem, são sensíveis às propriedades acústicas que demarcam as fronteiras de constituintes prosódicos, utilizando-se delas para segmentar o fluxo da fala em unidades gramaticalmente significativas (JUSCZYK et al., 1992; CHRISTOPHE et al., 1994; GOUT; CHRISTOPHE; MORGAN, 2004; SEIDL; CRISTIÀ, 2008; MANNEL; FRIEDERICI, 2009). Desse modo, investigamos se fenômeno semelhante ocorre no PB.

\subsection{Metodologia}

A fim de observarmos se os bebês brasileiros são sensíveis às informações acústicas contidas nas fronteiras de I, desenvolvemos um experimento com a técnica de Olhar Preferencial (Preferential Looking - variação da técnica de Escuta Preferencial Headturn Preference Procedure) (cf. NAME, 2012; NAME; CORRÊA, 2006). Essas técnicas se baseiam no pressuposto de que o bebê terá uma reação comportamental distinta se perceber alguma diferença entre estímulos sonoros apresentados em uma condição experimental comparada à outra. Ainda, explora-se uma relação de contingência entre estímulo e comportamento, já que a apresentação do estímulo sonoro depende do interesse/comportamento do bebê, que escuta o estímulo enquanto estiver olhando na direção de onde vem o som. Se ele desviar o olhar por mais de dois segundos, a emissão de som é interrompida, e um novo ciclo começa.

A técnica de Olhar Preferencial se desenvolve em quatro fases: pré-teste, familiarização, teste e pós-teste. Interessam-nos as fases de familiarização e de teste, que serão detalhadas. As demais têm os objetivos de acostumar o bebê ao procedimento experimental (pré-teste) e de assegurar seu interesse até o fim da atividade (pós-teste). Nessas fases, são apresentadas uma mesma imagem e os mesmos estímulos sonoros (frases curtas, como “Olá! Tudo bem com você?’).

Na fase de familiarização, é exibida a mesma imagem no pré-teste, acompanhada por um estímulo linguístico. 0 objetivo é fazer com que o bebê se acostume com um 
dado estímulo, a fim de reconhecê-lo posteriormente na fase de teste (NAME, 2012). No experimento que desenvolvemos, essa fase durou dois minutos, durante os quais as crianças escutaram uma única palavra apresentada em contornos prosódicos variados. Como veremos adiante, os bebês foram distribuídos em dois grupos: grupo BARCO, familiarizado à palavra BARCO, e grupo BAR, familiarizado à palavra BAR.

Em seguida, começa a fase de teste. É exibida a mesma imagem utilizada no préteste e na familiarização, acompanhada por estímulos linguísticos congruentes ou não com aqueles que foram apresentados na familiarização. A finalidade é verificar se o bebê faz distinção entre o que lhe é familiar ou não. A apresentação dos estímulos é controlada pelo bebê, pois o som e a imagem são interrompidos se o bebê desviar o olhar da direção de onde vem o som. 0 pesquisador mede o tempo que a criança olha para a tela, que corresponde ao tempo de escuta do estímulo, comparando essa medida entre as condições apresentadas. A despeito do nome, a medida usada é de preferência pelo enunciado ouvido. A aferição do tempo de olhar/escuta permite verificar se a criança percebeu a distinção entre os estímulos que lhe foram apresentados. A apresentação dos estímulos e a aferição dos tempos de reação dos bebês foram realizadas através do software Habit (COHEN; ATKINSON; CHAPUT, 2000). Através do Habit, o experimentador pode aferir, com maior precisão e controle, o tempo de olhar do bebê, que equivale ao tempo de escuta do estímulo apresentado.

Como o presente trabalho objetiva investigar se os bebês são sensíveis às informações acústicas presentes nas fronteiras de I e a influência destas no processo de segmentação do continuum da fala, elaboramos condições experimentais que pudessem captar como essas fronteiras atuam no processamento do sinal acústico da fala. Elegemos as palavras isoladas BAR e BARCO para serem apresentadas na fase de familiarização. Para a fase de teste, foram construídos seis pares de sentenças experimentais, divididos em duas condições (ambas apresentadas ao bebê nesta fase) utilizando-se como alvos as palavras supracitadas: Na condição 1, temos a palavra BARCO seguida de uma fronteira de I. Na condição 2, temos a palavra BAR seguida de uma fronteira de I. Após essa fronteira, temos um verbo trissilábico, como por exemplo, COCHILA, cuja primeira sílaba é homófona à última sílaba do dissílabo BARCO. Essa sílaba, associada ao monossílabo tônico BAR antecedente na estrutura sentencial, pode 
fazer com que o participante tenha a "ilusão" de ter ouvido a palavra BARCO. Os pares de sentenças confrontam os dois tipos de estrutura:

Condição 1 -BARCO (I): [A sócia do nosso BARCO] I [fechou contrato com turistas]. Condição 2 -BAR (I) CO: [A sócia do nosso BAR] I [cochila durante o trabalho].

As sentenças foram gravadas por uma falante nativa do PB utilizando a FDC. A leitura das frases foi realizada do modo mais natural possível. As gravações foram capturadas através de um gravador de voz digital (SONY PCM-D50) e realizadas no Laboratório de Atividades Experimentais do NEALP, ambiente com isolamento acústico, que eliminou a interferência de ruídos externos. Utilizando os dados de uma só participante, buscamos garantir a uniformidade entre as sentenças, para que fosse possível comparar as propriedades prosódicas que sinalizam uma fronteira de I. Dessa forma, garantimos que todos os bebês testados fossem expostos a estímulos linguísticos da mesma origem.

As gravações obtidas para o desenvolvimento da atividade experimental foram analisadas acusticamente, considerando-se os seguintes parâmetros suprassegmentais: (i) a duração, em milésimos de segundo, das pausas e do alongamento de vogal préfronteira de I e (ii) a curva de frequência fundamental (F0), bem como seus valores máximos nos segmentos críticos. A escolha pelos valores máximos de F0 e de intensidade justifica-se por serem eles os mais reportados na literatura acerca da percepção das características prosódicas da fala por bebês (SEIDL; CRISTIÀ, 2008; MANNEL; FRIEDERICI, 2009). Esses valores foram obtidos através do software PRAAT e determinados com base nas informações auditivas e na interpretação do espectrograma e da forma da onda sonora dos estímulos. As análises acústicas empreendidas no presente trabalho recobrem as sílabas que estão no entorno das fronteiras de I.

Em primeiro lugar, analisamos as pausas, que foram encontradas em todas as sentenças, demarcando as fronteiras de I. Em média, esses intervalos tiveram a duração de 260 ms. Tais pausas são características das fronteiras de I, descritas como pausas de retomada nas quais há um declive na curva de frequência fundamental (F0) no fim de um I, seguido por uma retomada, após as pausas, do nível tonal no I seguinte. De acordo com Goldman-Eisler (1972), embora as pausas exerçam funções pragmáticas e 
paralinguísticas, elas são, comumente, associadas a fronteiras no continuum da fala em diversas línguas naturais. Em decorrência disso, as crianças, na delimitação de unidades sintáticas, atentam, principalmente, para a presença de pausas. Como vimos na descrição das características prosódicas da FDC, as pausas são informações acústicas muito presentes nesse registro de fala. A duração das pausas é consideravelmente mais longa na FDC do que na FDA (COOPER; PACCIA-COOPER, 1980; SCOTT, 1982), fenômeno também verificado nas análises acústicas dos dados de FDC espontâneos desenvolvidas no presente trabalho. Dessa maneira, defendemos que esse correlato acústico desempenha um papel preponderante na percepção de uma fronteira de I pelos bebês em fase inicial do processo de aquisição da linguagem.

Em seguida, investigamos a diferença de duração entre a unidade BAR como um monossílabo tônico e como a primeira sílaba da palavra BARCO. Quando BAR era uma palavra monossilábica, sua duração média foi de 602 ms. Quando esse item era parte integrante de BARCO, sua duração média foi de 533 ms. Tal diferença foi estatisticamente significativa $(\mathrm{p}<0.004)$ e pode ser justificada pelo fato de a sílaba na palavra BAR portar proeminência acentual e por estar em posição de fronteira de I. Ainda em relação ao parâmetro de duração, analisamos a sílaba CO em BARCO (I) e em BAR (I) CO. A duração média da última sílaba de BARCO foi de $202 \mathrm{~ms}$, enquanto a duração média da mesma sílaba em BAR (I) CO foi de $174 \mathrm{~ms}$, ou seja, houve um alongamento da vogal da sílaba CO em posição pré-fronteira de I. Essa diferença foi estatisticamente significativa ( $p=0.023$ ). (cf. COOPER; PACCIA; COOPER, 1980; FROTA, 2000; SEVERINO, 2011).

O segundo parâmetro acústico analisado foi a curva de F0. Em concordância com o que é apresentado pela literatura (FERNALD et al., 1989; SEIDL; CRISTIÀ, 2008; MANNEL; FRIEDERICI, 2009; SCARPA; FERNANDES-SVARTMAN, 2012; FROTA, BUTLER; VIGÁRIO, 2013), os valores de F0 na FDC são muito mais elevados do que aqueles encontrados na FDA. Nos estímulos linguísticos utilizados no experimento, as medidas da F0 alcançaram picos de $500 \mathrm{~Hz}$. De acordo com Ladd (2008), uma fronteira sintática pode ser demarcada por uma descontinuidade no contorno da F0, fenômeno descrito pelo autor como pitch reset. De acordo com essa abordagem, uma diferença de pitch é definida como a diferença entre o valor de F0 no fim de um sintagma ou enunciado e o valor de F0 no início do sintagma ou enunciado subsequente. 
Nos domínios das fronteiras de I presentes nas sentenças experimentais, observamos um contorno entoacional fall-rise: houve um declive na curva de F0 no fim de um I, seguido por uma retomada, após as pausas, do nível do tom no início do I seguinte. Em outras palavras, o valor da F0 das sílabas pós-fronteira foi mais alto do que o valor desse parâmetro nas sílabas pré-fronteira (cf. FROTA, 2000). Dessa maneira, foram analisadas as sílabas localizadas nos limites da fronteira de I. Na condição 1 (BARCO (I)), o valor médio da F0 foi de $282 \mathrm{~Hz}$ antes da fronteira de I e de $477 \mathrm{~Hz}$ depois da fronteira. Em termos estatísticos, essa diferença foi significativa: $\mathrm{p}=0.006 \mathrm{Na}$ condição 2 ( BAR (I) CO), a média dos valores de F0 foi de $260 \mathrm{~Hz}$ antes da fronteira e de $437 \mathrm{~Hz}$ após a fronteira. Essa diferença também foi estatisticamente significativa: $\mathrm{p}<$ 0.001. Esses resultados vão ao encontro do que apresentam Cooper e Sorensen (1977).

Segundo os autores, os adultos tendem a decrescer o contorno de F0 ao longo de enunciados declarativos. Assim, o valor do pitch da primeira sílaba do sintagma ou enunciado subsequente (sílaba pós-fronteira) é mais alto do que o valor do pitch da sílaba pré-fronteira, padrão conhecido como fall-rise. Ladd (2008) argumenta que as variações de pitch são, normalmente, maiores no final de um enunciado do que no nível dos sintagmas ou nas fronteiras entre palavras. Por conta desse padrão fall-rise, o domínio de uma fronteira de I é delimitado por um tom de fronteira baixo (L\%), seguido de uma retomada do nível da curva de F0 que apresenta, no sintagma seguinte, um tom de tessitura alta ( $\mathrm{H}$ ou $\left.\mathrm{H}+\mathrm{L}^{*}\right)$.

As análises acústicas desenvolvidas examinaram a produção de informações prosódicas que atuam como correlatos acústicos das fronteiras de I na FDC (duração das pausas, variações de pitch e alongamento das vogais pré-fronteira). Todos esses correlatos foram produzidos pela leitora das sentenças experimentais. Tais resultados vão ao encontro de trabalhos que evidenciaram que as fronteiras de palavras e sentenças podem ser marcadas na fala fluente por traços prosódicos, os quais tendem a ser ampliados na FDC (SEIDL; CRISTIÀ, 2008). Realizadas essas análises, procedemos à realização do experimento. 
Hipótese e Previsões

Nossa hipótese é que, por volta dos treze meses de idade, o bebê é sensível às informações acústicas presentes nas fronteiras de I, utilizando-se delas na segmentação do fluxo da fala. Tendo em vista essa hipótese, nossa previsão é que bebês do Grupo BARCO (familiarizados com a palavra BARCO) reconhecerão a palavra familiarizada nas sentenças da condição 1 (BARCO (I)), havendo diferença estatisticamente significativa entre os tempos médios de olhar/escuta das duas condições. A ideia é que as pistas disponíveis nos domínios da fronteira de I são fortes o suficiente para impedir que a criança acesse a palavra BARCO na condição em que ela esteja presente apenas "virtualmente", isto é, na condição em que a fronteira está justamente entre a palavra BAR e a primeira sílaba (CO) das palavras subsequentes. Já para os bebês do Grupo BAR (familiarizados com a palavra BAR), nossa previsão é que eles podem reconhecer tal palavra em ambas as condições, pois, apesar das diferenças acústicas encontradas, essa sílaba é anterior à fronteira de I em ambos os tipos de sentença (BAR e BARCO) e não tem o seu reconhecimento bloqueado em nenhum deles.

\section{Material}

Seis pares de sentenças experimentais ${ }^{3}$.

\section{Variável independente}

Temos como variável independente a posição da fronteira de I, com dois níveis: (i) fronteira de I após os segmentos críticos (i.e., palavra BARCO seguida de fronteira de I); e (ii) fronteira de I entre os segmentos críticos (i.e., palavra BAR seguida de fronteira de I e da sílaba CO da palavra subsequente (verbo trissilábico)).

\footnotetext{
${ }^{3}$ Ver exemplo na subseção Metodologia, em Condição 1 e Condição 2. As sentenças experimentais podem ser consultadas em Silva (2014).
} 
Variável dependente

A variável dependente corresponde ao tempo de olhar/escuta exibido pelos bebês. Essa medida é aferida em segundos.

\section{Participantes}

Foram recrutados 20 bebês brasileiros, com média de idade de 13 meses. Desse conjunto de bebês, 4 foram eliminados pelos seguintes motivos: problemas técnicos, choro e não cumprimento da atividade até o fim. Assim, participaram do experimento 16 infantes, divididos, igualmente, em dois grupos.

\section{Procedimento}

A atividade experimental foi desenvolvida no Laboratório de Atividades Experimentais no NEALP - Núcleo de Estudos em Aquisição da Linguagem e Psicolinguística - da UFJF, num ambiente com isolamento acústico, projetado para diminuir a influência de manifestações sonoras externas, e utilizou-se a técnica do Olhar Preferencial.

Durante a fase de familiarização, os dois grupos de bebês foram expostos, durante dois minutos, a estímulos linguísticos formados por uma única palavra: 0 grupo BARCO foi familiarizado à palavra BARCO e o grupo BAR foi familiarizado à palavra BAR. É importante ressaltar que as palavras foram produzidas com diferentes contornos prosódicos e separadas por pausas de um segundo.

$\mathrm{Na}$ fase de teste, todos os bebês foram expostos a sentenças de ambas as condições, isto é, congruentes (estímulos-alvo iguais aos que foram exibidos na fase de familiarização) e incongruentes (estímulos-alvo diferentes daqueles que foram exibidos na familiarização). Apresentaram-se três ensaios (trials) por condição, coerentes ou não com o que foi apresentado na fase de familiarização. Por exemplo, a condição 1, abaixo, era congruente para o grupo BARCO e incongruente para o grupo BAR; inversamente, a condição 2 era congruente para o grupo BAR e incongruente para o grupo BARCO. 
Condição 1 - BARCO (I): [A sócia do nosso BARCO] I [fechou contrato com turistas].

Condição 2 - BAR (I) CO: [A sócia do nosso BAR] I [cochila durante o trabalho].

\section{Resultados e discussão}

Os resultados de ambos os grupos apontam para uma preferência pelos estímulos congruentes à familiarização. Os bebês do grupo BAR ouviram, em média, 12,2 segundos os estímulos da condição BAR e 11,7 segundos os da condição BARCO, congruente e incongruente, respectivamente. Inversamente, os bebês do grupo BARCO ouviram por 14,3 segundos a condição BARCO (congruente) e 8,8 segundos a condição BAR (incongruente).

O gráfico a seguir mostra as médias dos tempos de reação (que equivalem ao tempo de escuta dos estímulos) em segundos dos diferentes grupos de bebês (BAR e BARCO) nas condições congruente e incongruente:

Figura 1: Média dos tempos de reação em segundos dos dois grupos de bebês

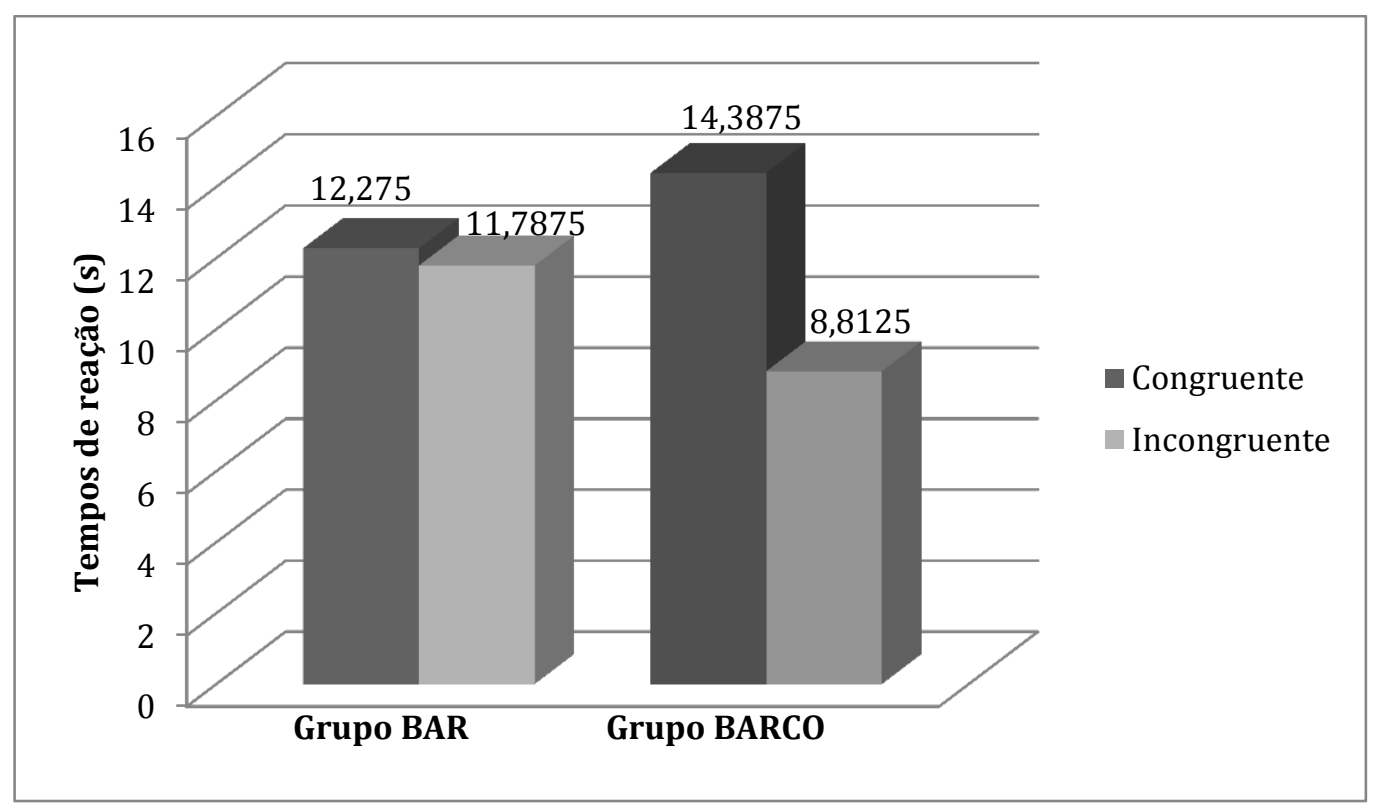

Os dados foram submetidos a ANOVA de medidas repetidas com design fatorial 2x2. Os fatores verificados foram: Categoria (congruente versus incongruente) como fator intra sujeitos e Familiarização (Bar versus Barco) como fator dentre sujeitos. Houve um efeito principal de Categoria: $F(1,14)=11,3$, $p<0,0046$. Não houve efeito significativo 
do fator Familiarização: $F(1,14)=0,076, p<0,787468$. Ainda, a interação entre os fatores foi significativa $(F(1,14)=7,95, p<0,013)$.

Foram realizadas, ainda, análises estatísticas por grupo (teste-t). No grupo BARCO, foi encontrada diferença estatisticamente significativa entre as médias de tempo de escuta/olhar das duas condições $(\mathrm{t}(7)=5,63 \mathrm{p}<0,0008)$. Ao analisarmos as médias dos tempos de reação por bebê, observamos que todos os bebês desse grupo preferiram ouvir a condição congruente.

Bebês familiarizados com a palavra BAR preferiram ouvir sentenças da condição $\mathrm{BAR}$, mas a diferença entre as médias das duas condições não foi significativa $(\mathrm{t}(7)=0,32$ p<0,7559). Quando observamos os tempos de reação por bebê, notamos que metade deles preferiu ouvir sentenças congruentes (BAR) e metade preferiu ouvir as sentenças incongruentes (BARCO).

Os resultados do experimento desenvolvido com os bebês do grupo BARCO são bastante robustos e sugerem que as propriedades prosódicas localizadas nas fronteiras de I foram fortes o suficiente para impedir que os bebês reconhecessem a palavra BARCO nas sentenças em que essa palavra estava presente apenas de maneira "virtual", ou seja, na condição em que as sílabas BAR e CO estavam separadas por uma fronteira de I. Isso implica dizer que os bebês brasileiros, com idade média de 13 meses, são sensíveis a tais propriedades, utilizando-as como pistas para a segmentação do fluxo da fala.

\section{Conclusão}

A partir das análises acústicas dos dados espontâneos da FDC obtidos nas gravações e das sentenças experimentais desenvolvidas no presente estudo, podemos concluir que existem, nesse registro de fala, informações prosódicas robustas que sinalizam a presença das fronteiras de I, como variações significativas na curva de F0, alongamento de vogais pré-fronteira e presença de pausas silenciosas. Os resultados encontrados na atividade realizada com a técnica do Olhar Preferencial nos sugerem que bebês brasileiros, por volta dos treze meses de idade, são sensíveis a tais correlatos acústicos, utilizando-os como pistas para segmentar a fala fluente. Em outras palavras, podemos defender, com base em nossos resultados, que os bebês, desde muito cedo, são 
capazes de perceber as propriedades prosódicas que delimitam as fronteiras I, as quais sinalizam rupturas no fluxo da fala.

Desse modo, concluímos que o processo de aquisição da linguagem tem início muito antes de a criança dominar as estruturas lexicais e sintáticas de sua língua materna. Em conformidade com a hipótese do Bootstrapping Prosódico (MORGAN; DEMUTH, 1996; CHRISTOPHE et al., 1997), através de uma análise puramente acústica dos enunciados linguísticos aos quais é exposto, o bebê tem acesso à estrutura suprassegmental da língua de seu meio, fazendo uso das informações desse nível na organização da cadeia da fala e na delimitação de suas unidades passíveis de significação.

Considerando-se a relação que se estabelece, ainda que não perfeitamente, entre prosódia e sintaxe no domínio do sintagma entoacional ${ }^{4}$, já que suas fronteiras coincidem com fronteiras sintáticas (NESPOR; VOGEL, 1986; SELKIRK, 1984), podemos supor que esse constituinte prosódico facilitaria o processamento sintático, restringindo o "espaço" no qual as relações sintáticas seriam reconhecidas. Como apontam Corrêa e Augusto (2007):

no que diz respeito ao parsing, assume-se que uma representação de elementos lexicais segmentados e reconhecidos, correspondentes, grosso modo, a unidades prosódicas e sintáticas (ainda que questões de tamanho possam interferir) é mantida temporariamente em uma janela de processamento e o sistema computacional irá atuar sobre esses itens. (CORRÊA; AUGUSTO, 2007, p. 176).

No caso da aquisição de uma língua pelo bebê, em vez de representação de elementos "segmentados e reconhecidos", as unidades prosódicas mantidas temporariamente em uma janela de processamento facilitariam a aquisição lexical e sintática. Sendo assim, as fronteiras de sintagma entoacional teriam um papel fundamental no processo de aquisição da linguagem.

Por fim, vale destacar que temos, pela primeira vez no PB, a caracterização dos parâmetros acústicos de fronteira de I na FDC. São inéditos, também, nossos resultados relativos à sensibilidade de bebês brasileiros a tais propriedades acústicas. Esperamos que este trabalho contribua para nosso entendimento do processo de aquisição da

\footnotetext{
${ }^{4}$ As autoras defendem que essa relação também se dá no domínio do sintagma fonológico, não explorado neste trabalho.
} 
linguagem em geral, e do $\mathrm{PB}$ em particular, e motive o desenvolvimento de novas pesquisas.

\section{Referências}

BISOL, L. Os constituintes prosódicos. In: (Org.) Introdução a estudos de fonologia do português brasileiro. 3. ed. Porto Alegre: Editora da PUCRS, 2001, p. 259-271.

BOERSMA, P.; WEENICK, D. PRAAT: doing phonetics by computer (version: 5.3.53), 2013. Disponível em: http://www.praat.org/.

CAVALCANTE, M. C. B.; BARROS, A. T. M. C. Manhês: qualidade vocal e deslocamento na dialogia mãe-bebê. Veredas, Edição Especial VIII ENAL - II EIAL, 2012, p. 25-39.

CHOMSKY, N. The Minimalist Program. Cambridge, Mass: MIT Press, 1995.

CHRISTOPHE, A.; DUPOUX, E.; BERTONCINI, J.; MEHLER, J. Do infants perceive word boundaries? An empirical study of the bootstrapping of lexical acquisition. Journal of The Acoustical Society of America, v. 95, 1994, p. 1570-1580.

CHRISTOPHE, A.; GUASTI, T.; NESPOR, M.; DUPOUX, E.; VAN OOYEN, B. Reflections on phonological bootstrapping: its role for lexical and syntactic acquisition. Language and Cognitive Processes, v. 12, n. 5/6, p. 585-612, 1997.

COHEN, L. B.; ATKINSON, D. J.; CHAPUT, H.H. Habit 2000: A new program for testing infant perception and cognition (Version 2.25c) [Computer software]. Austin: The University of Texas.

COOPER, W. E.; PACCIA-COOPER, J. Syntax and speech. Cambridge: Harvard University Press, 1980.

COOPER, W. E.; SORENSEN, J. M. Fundamental frequency contours at syntactic boundaries. Journal of The Acoustical Society of America, v. 62, p. 683-692, 1977.

CORRÊA, L. M. S. Conciliando processamento linguístico e teoria de língua no estudo da aquisição da linguagem. In: (Org.) Aquisição da linguagem e problemas do desenvolvimento linguístico. Rio de Janeiro: Ed. PUC-Rio; São Paulo: Loyola, 2006, p. 2178.

CORRÊA, L. M. S., AUGUSTO, M. R. A. Computação linguística no processamento on-line: soluções formais para a incorporação de uma derivação minimalista em modelos de processamento. Cadernos de Estudos Linguísticos (UNICAMP), p. 167-183, 2007.

FERNALD, A.; TAESCHER, T.; DUNN, J.; PAPOUSEK, M.; BOYSSON-BARDIES, B. D.; FUKUI, I. A cross-language study of prosodic modifications in mothers' and fathers' speech to preverbal infants. Journal of Child Language, v. 16, p. 477-501, 1989. 
FERNALD, A.; HURTADO, N. Names in frames: Infants interpret words in sentence frames than words in isolation. Developmental Science, v. 9, p. 33-40, 2006.

FROTA, S. Prosody and focus in European Portuguese: Phonological phrasing and intonation. New York: Garland Publishing, 2000.

FROTA, S.; BUTLER, J.; VIGÁRIO, M. Infant's perception of intonation: Is it a statement or a question? The Official Journal of The International Society on Infant Study, p. 1-20, 2013.

GOLDMAN-EISLER, F. Pauses, clauses, sentences. Language and Speech, v. 15, 1972, p. 103-113.

GOUT, A.; CHRISTOPHE, A.; MORGAN, J. Phonological phrase boundaries constrain lexical access: II Infant data. Journal of Memory and Language, v. 51, p. 548-567, 2004.

GUSSENHOVEN, C. The phonology of tone and intonation. Cambridge: Cambridge University Press, 2004.

JUSCZYK, P. W.; KEMLER-NELSON, D. G.; HIRSH-PASEK, K.; KENNEDY, L.; WOODWARD, A.; PIWOZ, J. Perception of acoustic correlates of major phrasal units by young infants. Cognitive Psychology, v. 24, p. 252-293, 1992.

LADD, D. R. Intonational Phonology. Cambridge: Cambridge University Press, 2008.

LADEFOGED, P. Vowels and consonants: An introduction to the sounds of languages. Oxford: Blackwells, 2001.

LEE, S.; DAVIS. B. L.; MACNEILAGE, P. F. Segmental properties of input to infants: a study of Korean. Journal of Child Language, v. 35, n. 3, p. 591-617, 2008.

MANNEL, C.; FRIEDERICI, A. D. Pauses and Intonational Phrasing: ERP Studies in 5month-old German infants and adults. Journal of Cognitive Neuroscience, v. 21, n. 10, p. 1988-2006, 2009.

MATSUOKA, A.; NAME, M. C. O uso de pistas prosódicas na identificação do adjetivo por crianças e adultos falantes do PB. Anais do VII Congresso Internacional da ABRALIN, Curitiba, p. 577-587, 2011.

MCCLELLAND, J. L.; ELMAN, J. L. The trace model of speech perception. Cognitive Psychology, v. 18, p. 1-86, 1986.

MEHLER, J.; CHRISTOPHE, A. Language in the infant's mind. Philosophical Transactions: Biological Sciences, v. 346, n. 1315, p. 13-20, 1994.

MORGAN, J.L.; DEMUTH, K. Signal to syntax: An overview. In: (Eds.) Signal to syntax: Bootstrapping from speech to grammar in early acquisition. Mahwah, NJ: Lawrence Erlbaum Associates Inc., 1996, p. 1-22. 
NAME, M. C. O que nos dizem os resultados experimentais sobre a percepção da fala pelo bebê. Veredas, Edição Especial VIII ENAL - II EIAL, p. 282-295, 2012.

NAME, M. C.; CORREAA, L. M. S. Explorando a escuta, o olhar e o processamento sintático: metodologia experimental para o estudo da aquisição da língua materna em fase inicial. In: CORRÊA, L. M. S. (Org.) Aquisição da Linguagem e problemas do desenvolvimento linguístico. Rio de Janeiro: Ed. PUC-Rio; São Paulo: Loyola, 2006, p. 79-100.

NESPOR, M.; VOGEL, I. Prosodic Phonology: with a new foreword. Dordrecht-Holland: Foris Publications, 1986.

NORRIS, D. G. Shortlist: a connectionist model of continuous speech recognition. Cognition, v. 52, p. 189-234, 1994.

OCHS, E.; SCHIEFFELIN, B. B. 0 impacto da socialização da linguagem no desenvolvimento gramatical. In: FLETCHER, P.; MACWHINNEY, B. (Orgs.) Compêndio da Linguagem da Criança. Porto Alegre: Artes Médicas, 1995.

PIERREHUMBERT, J. The phonology and phonetics of English intonation. PhD Thesis. Massachussets: MIT, 1980.

SCARPA, E.; FERNANDES-SVARTMAN, F. Entoação e léxico inicial. Veredas, Edição Especial VIII ENAL - II EIAL, p. 40-54, 2012.

SCOTT, D. Durations as a cue to the perception of a phrase boundary. Journal of the Acoustical Society of America, v. 71, p. 996-1007, 1982.

SEIDL, A.; CRISTIÀ, A. Developmental changes in the weighting of prosodic cues. Developmental Science, v. 11, n. 4, p. 596-606, 2008.

SELKIRK, E. O. Phonology and syntax: the relation between sound and strucuture. Cambridge: Cambridge University Press, 1984.

SEVERINO, C. S. Fronteiras prosódicas e desambiguação no Português Europeu. Dissertação de mestrado. Universidade de Lisboa, 2011.

SILVA, Í. O. A sensibilidade de bebês brasileiros a fronteiras de sintagma entoacional: a prosódia nas fases iniciais da aquisição da linguagem. Dissertação de mestrado. Universidade Federal de Juiz de Fora, 2014.

SNOW, C. E. Mothers' speech to children learning language. Child Development, v. 43, p. 549-565, 1972.

SODERSTROM, M. Beyond babytalk: Re-evaluating the nature and content of speech input to preverbal infants. Developmental Review, v. 27, p. 501-532, 2007. 
WEPPELMAN, T. L.; BOSTOW, A.; SCHIFFER, R.; ELBERT-PEREZ, E.; NEWMAN, R. S. Language \& Communication, v. 23, p. 63-80, 2003.

Recebido em março de 2014.

Aceito em junho de 2014. 